\title{
Proteomic analysis of extremely stable soluble high molecular mass multi-protein complex of human placenta
}

\author{
E. Burkova ${ }^{1 *}$, G. Nevinsky ${ }^{1,2}$ \\ ${ }^{1}$ Institute of Chemical Biology and Fundamental Medicine SB RAS, Novosibirsk, Russia \\ ${ }^{2}$ Novosibirsk State University, Novosibirsk, Russia \\ *e-mail:burkova_evgeniya_e@mail.ru
}

Key words: placenta, protein complex, catalytic activities

Motivation and Aim: Many biological function of placenta are performed not just a set of individual proteins, but also different oligomeric structures and complexes. Herewith activities of complexes may considerably differ from activities of individual proteins. The research of protein complexes will allow to characterize some molecular mechanisms of functioning of placenta more fully. We recently obtained from human placenta an extremely stable multi-protein complex (SPC, $\sim 1000 \mathrm{kDa})[1]$. This complex possesses DNase and catalase activities $[1,2]$. The aim of the present work was to investigate a protein composition and catalytic activities of the extremely stable high molecular mass multi-protein complexes (SPC) from placenta of healthy mother.

Methods and Algorithms: We identified the proteins of SPCs by MALDI mass MS and MS/MS spectrometry using proteins tryptic hydrolyzates after proteins separation by 1D- and 2D-electrophoresis. Also we analyzed catalytic activities of this very stable complex.

Results: It was shown that SPCs contain twelve proteins and their different isoforms: hemoglobin, alkaline phosphatase, cytoplasmic actin, human serum albumin, chorionic somatomammotropin hormone, heart shock protein beta-1, peroxiredoxin-1, $78 \mathrm{kDa}$ glucose-regulated protein, protein disulfide isomerase A3, serotransferrin, annexin A5, and IgGs. It was shown the SPCs possess RNase, peroxidase $\left(\mathrm{H}_{2} \mathrm{O}_{2}\right.$-dependent $)$ and oxidoreductase $\left(\mathrm{H}_{2} \mathrm{O}_{2}\right.$-independent) activities. An addition, investigation of cytotoxic effect on human cancerous cell lines has shown that the SPCs reveal high cytotoxicity. Conclusion: Progress in the study of placental protein complexes can promote understanding of their biological functions.

Acknowledgements: Supported by Russian State funded budget project (VI.62.1.5, 03092016-0003), Grant of RFBR No. 16-04-00609.

\section{References}

1. Burkova E.E., Dmitrenok P.S., Sedykh S.E., Buneva V.N., Soboleva S.E., Nevinsky G.A. (2014) Extremely stable soluble high molecular mass multi-protein complex with DNase activity in human placental tissue. PLoS One. 9(11):e111234.

2. Burkova E.E., Nevinsky G.A. (2016) Very stable high molecular mass multi-protein complex from human placenta. FEBS J. 283(Suppl. S1):211. 